\title{
GÊNERO E REPRESENTAÇÃO POLÍTICA: UM ESTUDO SOBRE A REPRESENTAÇÃO SINDICAL DE TRABALHADORAS/ES EM EDUCAÇÃO'
}

\author{
Márcia Ondina Vieira Ferreira \\ Universidade Federal de Pelotas (UFPel), Pelotas, Rio Grande do Sul, \\ Brasil \\ AndRÉIA OrSATO \\ Instituto Federal de Educação Ciência e Tecnologia Sul-Rio-Grandense \\ (IFSul), Rio Grande do Sul, Brasil \\ Márcia Cristiane Völz Klumb Coronel \\ Luciano Pereira dos Santos \\ Universidade Federal de Pelotas (UFPel), Pelotas, Rio Grande do Sul, \\ Brasil
}

Resumo: O artigo parte da insuficiência de estudos sobre gênero em sindicatos de educação no Brasil. Observamos que os poucos trabalhos existentes dedicam-se a discutir a participação sindical das mulheres, sem ingressar mais diretamente na posição dos próprios sindicatos. Sabendo que diferenças de gênero e de diversidade sexual são componentes de processos de distribuição de poder e desigualdade social, tivemos por objetivo verificar a proporcionalidade entre homens e mulheres ocupantes de cargos diretivos em sindicatos filiados à CNTE. Para tanto, realizamos levantamentos nos sites da CNTE e de seus sindicatos. Quanto à divisão de poder por sexo, constatamos que, tal como ocorre em outros espaços institucionais como no Legislativo e no Executivo brasileiros, a presença masculina ainda é maior.

Palavras-chave: Relações de gênero. Participação da mulher. Sindicatos de trabalhadores em educação. CNTE.

\section{CARACTERIZAÇÃO DO ESTUDO}

[...] as normas pelas quais as mulheres são medidas nada têm de universais. Bourdieu, 1999, p. 78

No Brasil existem poucos estudos versando sobre relações de gênero em sindicatos de trabalhadoras/es em educação, constatação que muito possivelmente pode ser transladada a outras paragens. Pode-se apreender esse movimento a partir de estudo recente, que identificou apenas seis dissertações e duas teses que tratavam sobre o tema no Brasil, realizadas entre 1987 e 2011 (CORONEL, 2014). O objeto prioritário em quase 
todas essas pesquisas era a situação da professora em termos de participação e reconhecimento nos sindicatos e no movimento docente. Apenas um dos estudos tinha preocupação com o caráter relacional do gênero, buscando a existência de particularidades no agir coletivo conforme a condição de gênero de ativistas. Da mesma forma, em levantamento realizado na página WEB da ANPEd - Associação Nacional de Pós-Graduação e Pesquisa em Educação -, entre os anos 2000/2009, priorizando os Grupos de Trabalho (GT) 02 (História da Educação), 03 (Movimentos Sociais e Educação), 09 (Trabalho e Educação), 14 (Sociologia da Educação) e 23 (Gênero, Sexualidade e Educação), foram encontrados apenas seis textos (trabalhos e pôsteres) que usavam a categoria gênero dentre os 11 textos sobre a organização sindical docente. Três desses seis textos foram apresentados no GT 03, e os demais nos GTs 2, 9, e 23.

É possível indicar dois principais motivos pelos quais prepondera a invisibilidade do gênero na análise sobre sindicalismo docente, tomadas por similitude, também, com estudos sobre gênero e sindicalismo em geral. Um deles decorre do fato de que a organização sindical foi criada para ser palco de atuação de homens; diz-se, então, que o masculino é tomado como o neutro universal (HUMPHREY, 1983). Outro motivo resulta da própria preocupação prioritária dos sindicatos, as lutas em defesa do salário e condições de trabalho, que se baseiam na ideia de unidade e universalidade da classe trabalhadora (STREET, 2008). Ou seja, apenas muito recentemente os sindicatos estão dando maior atenção a particularidades de grupos que compõem a base de suas organizações. Neste sentido, observa-se que tanto as análises sobre sindicatos quanto a ação dos mesmos apresentam-se, segundo autoras, enviesados do ponto de vista do gênero, lendo o mundo com lentes masculinas (SOUZA-LOBO, 1991; ROGERAT; ZYLBERBERG-HOCQUARD, 2009). Ademais, devemos ter em vista o fato de que a história dos estudos sobre a divisão social do trabalho entre os sexos, ou simplesmente divisão sexual do trabalho - estudos fundamentais para a percepção da importância das diferenças de gênero no processo de produção - revela que esses somente começaram a se desenvolver a partir da segunda onda do feminismo, nos anos 1970. A teorização sobre a divisão sexual do trabalho tem sido um processo, assim, pleno de desconstruções e reconstruções (HIRATA; KERGOAT, 2008; KERGOAT, 2009), de forma que seria incoerente esperarmos uma perspectiva diferente no que se refere aos estudos sobre sindicalismo.

Por outra parte, diferentemente de outros campos de análise da representação das mulheres, é inegável que a presença de mulheres ativistas em sindicatos da área de educação é numericamente superior à sua participação paritária em outras instâncias da sociedade, especialmente quando a atuação implica tomada de decisão. Entretanto, parece-nos que mesmo nesses sindicatos as mulheres estão sub representadas, cabendo investigar como as representações culturais dominantes sobre o que compete a homens e a mulheres interferem na distribuição de poder.

Neste sentido, este texto pretende colaborar no preenchimento de lacunas quanto ao levantamento e análise de informações sobre participação de mulheres quanto à representação sindical de trabalhadoras/es em educação, de tal maneira que podemos identificar nosso objetivo como: verificar a proporcionalidade entre homens e mulheres ocupantes de cargos diretivos em sindicatos filiados à CNTE/Brasil (Confederação Nacional dos Trabalhadores em Educação). 
Para tanto, realizamos levantamentos nos sites da CNTE e de seus sindicatos, visando produzir um mapeamento da presença masculina e feminina em cargos de poder (nominatas das diretorias centrais). Deparamo-nos, primeiramente, com uma grande quantidade de informações e com dificuldades para fazer contatos com alguns sindicatos que: ou não possuem página $W E B$, ou não apresentam na mesma a nominata de suas diretorias, ou não responderam a contatos via e-mail ou telefone. À CNTE estão filiadas 50 entidades especialmente de caráter municipal e estadual, agrupando trabalhadoras/es em educação de variadas categorias. Frente a tal amplitude tomamos, como exemplário, em cada estado do país, o sindicato da educação básica com maior número de filiados, independentemente da rede de ensino.

Assim, são 25 o total de entidades selecionadas, considerando que no estado do Rio de Janeiro não há sindicato filiado à CNTE e que não conseguimos contato com o SINTEAC/AC (Sindicato dos Trabalhadores em Educação do Acre). Todos esses sindicatos contemplam a rede estadual e/ou as municipais, sendo que três deles contemplam também a rede federal de ensino. Contamos o número de mulheres e de homens das diretorias centrais de cada sindicato e estabelecemos a proporcionalidade entre os sexos. Ademais, resgatamos a presença de homens e de mulheres em cargos com maior grau de disputa política e prestígio: presidência, secretaria geral e tesouraria. Quanto aos demais cargos, foram contados em conjunto. Os dados foram construídos entre maio e agosto de 2015.

Para compreender a situação desigual das mulheres em relação aos homens na esfera da representação, optamos por fazer uso de um referencial interdisciplinar, oriundo prioritariamente da sociologia e da filosofia política, sintetizado a seguir.

\section{ELEMENTOS DO FEMINISMO E DA DISCUSSÃO SOBRE GÊNERO NO MOVIMENTO SINDICAL BRASILEIRO}

Muito provavelmente a separação entre as esferas pública e privada seja um aspecto a reunir críticas feministas dos mais variados matizes e campos teóricos, e isso porque tal divisão naturaliza processos que não apenas garantem a desigualdade, mas instituem os lugares sociais e as identidades das pessoas nascidas sob cada um dos sexos. Assim, teóricas como Pateman (1993) destacam que os direitos individuais construídos na modernidade definiram a diferença entre o público e o privado, instituindo as mulheres como parte do contrato social, cujo elemento central seria a dominação dos homens sobre as mulheres e o direito masculino de acesso sexual regular a elas.

O pacto original, segundo a autora, cria, concomitantemente, a liberdade do homem e a sujeição da mulher. É dele que emerge a dicotomia entre o "natural/feminino" e o "civil/masculino", ou seja, a dicotomia entre esfera pública e privada, a qual está na base das explicações a respeito da ausência ou baixa representação feminina nos espaços de poder. A esfera privada não teria significado político relevante, em contraposição à pública. Enquanto a esfera pública seria identificada como o espaço da liberdade e da igualdade, a esfera privada estaria associada ao poder, à diferença e à dominação. Enquanto a primeira é simbolicamente conexa ao masculino, a segunda é associada ao feminino.

Nesses termos, Pateman (1993) contribui para problematizar a história do contrato, contada por contratualistas como Thomas Hobbes, John Locke e Jean-Jacques 
Rousseau, a qual silencia acerca do contrato sexual, ao mesmo tempo em que omite a exclusão das mulheres, resumindo-se a dizer que, por força da natureza, as mulheres não têm os predicados e as habilidades necessárias para as questões políticas. Dessa forma, o patriarcado moderno "é fraternal, contratual e estrutura a sociedade civil capitalista" (PATEMAN, 1993, p. 45), sendo que "as relações conjugais fazem parte de uma divisão sexual do trabalho e de uma estrutura de subordinação que se estende do lar privado à arena pública do mercado capitalista" (idem, ibidem, p. 170).

Contudo, mesmo entre teóricas feministas existe quem valorize a importância da esfera privada como local de promoção do afeto e do cuidado. Aqui há o risco "de retorno a um ideal do feminino que identifica a mulher com o amor e o afeto, em contraste com o estereótipo da agressividade masculina" (MIGUEL; BIROLI, 2013, p. 20). Para superar essa dificuldade, o autor e a autora pontuam a necessidade de associar o direito à privacidade à ampliação da autonomia dos indivíduos.

Outro destaque nessa ótica é a acepção de que a vivência mais íntima na esfera privada produz um tipo de ética, chamada de ética do cuidado ou do desvelo. As mulheres tenderiam, por sua criação, a ter um desenvolvimento moral que lhes predispõe a buscar soluções para problemas considerando cada caso; enquanto os homens, com um desenvolvimento moral voltado para princípios universais e abstratos, exerceriam uma ética da justiça. Essa análise é derivada das chamadas teorias da maternagem, tendo Carol Gilligan [s.d.] como uma de suas expoentes, motivo pelo qual a análise enfatiza a diferença de vozes - femininas e masculinas - no exercício da política (MIGUEL, 2001; KYMLICKA, 2006).

Por outra parte, implicações da cisão público/privado podem ser observadas na própria divisão do trabalho. O tempo que a mulher pode dedicar a atividades remuneradas, em especial as de maior prestígio, depende do tempo que lhe sobra após a realização do trabalho doméstico, de forma que homens e mulheres vão desenvolvendo habilidades diferenciadas. Na linha da dominação masculina como violência simbólica, Bourdieu (1999) afirma que a direção e a forma das mudanças da condição feminina estão atreladas às estruturas antigas de divisão sexual. Assim,

\begin{abstract}
além de estarem objetivadas nos níveis, carreira, nos cargos mais ou menos fortemente sexuados, elas atuam através de três princípios práticos [...]: as funções que convêm às mulheres se situam no prolongamento das funções domésticas: ensino, cuidados, serviço; segundo, que uma mulher não pode ter autoridade sobre homens e tem, portanto, todas as possibilidades de, sendo todas as coisas em tudo iguais, ver-se preterida por um homem para uma posição de autoridade ou de ser relegada a funções subordinadas, de auxiliar; o terceiro confere ao homem o monopólio da manutenção dos objetos técnicos e das máquinas (p. 112-113).
\end{abstract}

Segundo Kergoat (2009), a divisão sexual do trabalho apresenta dois princípios organizadores: o da separação (trabalhos de homens e trabalhos de mulheres) e o da hierarquização (o trabalho de um homem tem mais valor do que o de uma mulher). Mesmo sendo uma construção social, essa divisão está baseada na materialidade da divisão de trabalho, não sendo unicamente ideológica. Deve ser vista como estruturante dos campos sociais, embora mutantes segundo o tempo e o espaço. Dessa forma, 
examinar a divisão sexual do trabalho implica não apenas a descrição das tarefas distintas desenvolvidas por homens e mulheres no transcorrer dos tempos, mas a consideração das relações de poder que se expressam por meio dela.

Reflexões desse gênero têm gerado estudos preocupados em examinar como se produz o desenvolvimento não só dos diferentes tipos de ocupações segundo o sexo, mas também de que forma pessoas de sexos diferentes desenvolvem suas carreiras profissionais num mesmo ramo de atividade. Já existem dois termos incorporados ao jargão usado nessa linha: a carreira como teto de cristal para as mulheres e como escadarolante de vidro para os homens (WILLIAMS, 1992).

Ora, o que nos parece importante guardar de toda essa imbricada discussão é a profunda articulação entre questões de natureza cultural - presentes no habitus de homens e de mulheres -, de natureza política e de natureza econômica, sem privilegiar nenhum desses aspectos. A perspectiva de uma maior igualdade ou, melhor dizendo, de equidade entre homens e mulheres passa pelo reconhecimento de tal articulação, visando travar debates para promover a equidade.

É isso que, em alguma medida, propõe Fraser (2009) em seus escritos, tentando equacionar como se pode chegar a uma justiça distributiva na qual ocorra um melhor enquadramento dos sujeitos titulares de uma justa distribuição: "as teorias da justiça devem se tornar tridimensionais, incorporando a dimensão política da representação ao lado da dimensão econômica da distribuição e da dimensão cultural do reconhecimento" (FRASER, 2009, p. 17). Em termos das análises sobre a participação política das mulheres, essa seria, para a autora, uma forma de inclusão de grupos sociais subordinados e historicamente excluídos da arena política. Ao dar voz aos "contra públicos subalternos" (mulheres, trabalhadores, homossexuais e membros de grupos raciais específicos), esses teriam condições de formular suas próprias interpretações de identidade, interesses e necessidades.

A introdução da reflexão sobre gênero dentro do sindicalismo brasileiro também se baseou na crítica à disparidade, embora não possamos reduzir a discussão a esse aspecto. Os vários textos de Souza-Lobo (1991) a esse respeito relatam uma trajetória complexa, pois, como já dito, tanto os sindicatos quanto a sociologia do trabalho e a dos movimentos sociais apresentaram resistência em incorporar a problemática da mulher no trabalho e no sindicato. A emergência dessa discussão data do fim da década de 1970.

Nos anos 1980, segundo Giulani (2001), trabalhadoras rurais e urbanas já discutiam, no âmbito de suas atividades de participação política, o quanto as questões da esfera doméstica e da ocupacional estão articuladas, demarcando as relações de poder também na representação sindical. No âmbito da CUT isso conduziu à criação da Comissão Nacional sobre a Questão da Mulher Trabalhadora, em 1986 (CUT, 2016; CASTRO, 1995; GIULANI, 2001), enquanto a Força Sindical, segundo GIULANI (2001, p. 650), "institui em 1992 a Secretaria Nacional da Mulher, do Adolescente e da Criança". Contudo, para Marques e Costa (2009, p. 87), "na Força Sindical a Secretaria da Mulher surgiu na fundação da central, em 1991, e na CGT, em abril de 1986".

Consequência desses espaços conquistados pelas mulheres foi a instauração de cotas para ambos os sexos (mínimo de 30\% e máximo de 70\%) nas instâncias de direção das centrais sindicais. Conforme publicação da CUT (2016), a proposta de cotas foi aprovada na $6^{\circ}$ plenária em 1993, como recomendação e em 2008, na 12ª plenária, como 
resolução, passando a integrar seu estatuto. Em 2012, durante o $11^{\circ}$ Congresso Nacional da CUT (CONCUT), foi aprovada a paridade de gênero na direção central.

Quanto à Força Sindical, sua Secretária de Políticas da Mulher da Executiva Nacional 2016, Maria Auxiliadora dos Santos (2011), esclarece que as cotas (30\%) foram incorporadas nas diretrizes estatutárias em 1997, mas somente em 2009 a diretoria nacional da entidade conseguiu preencher a cota de $30 \%$ de mulheres.

Pelo que se deduz, considerando as várias décadas que separam o início desses debates até a consecução de uma cota mínima, a paridade realmente constitui uma realidade ainda não alcançada. $E$ isso porque é necessário não apenas uma igualdade numérica, mas lidar com as diferenças, reordenar os espaços organizacionais segundo essas diferenças, habilitar as mulheres para ocupar espaços e reeducar mulheres e homens para novas vivências de gênero (CASTRO, 1995).

No que se refere aos sindicatos de trabalhadoras/es em educação do ensino básico, pelo caráter feminizado das categorias que os compõem - na atualidade contamos com $80,1 \%$ de mulheres e com $19,9 \%$ de homens exercendo docência no ensino básico (INEP, 2016) -, não podemos falar em pouca presença de mulheres em direções sindicais, como veremos adiante. $\mathrm{O}$ que encontramos é uma desproporção entre os números de homens e mulheres na base e a representação masculina nas direções, em detrimento da feminina.

Vários trabalhos no campo da história da educação (ALMEIDA, 1998; LOURO, 2001) destacaram que o ingresso das mulheres na docência foi eivado de disputas, tendo se constituído em um dos locais de entrada no mercado de trabalho e em outros espaços públicos. Malgrado isso, as instituições educacionais herdaram a superioridade geométrica masculina, de tal forma que ainda podemos dizer que as professoras são chefiadas por homens, do chão da escola ao Ministério da Educação. As representações dominantes sobre o que compete à professora ressignificaram a escola, especialmente as séries iniciais, como um lugar não tão "público". Tais representações, associadas às condições objetivas de vida das mulheres, aparentemente constrangem sua superioridade aritmética. Assim, conforme Ferreira (2015, p. 313), pode-se concluir que o estudo da posição da mulher no movimento docente exige examinar as questões de gênero de maneira ampla, sendo necessário, por isso, "conhecer o processo de feminização da docência e como se articula o trabalho feminino com uma liderança preponderantemente masculina, no transcorrer do tempo".

Segundo alguns estudos, a participação das mulheres nas mobilizações e no cotidiano sindical padece dessas mesmas características. As dificuldades de participação das mulheres foram captadas por Coronel (2014) em seu estado da arte, de tal maneira que ela as separou, para fins analíticos, entre dificuldades exógenas (extrainstitucionais) e endógenas (intrainstitucionais). Na prática cotidiana, ambos tipos de dificuldades podem atuar concomitantemente. Os elementos dificultadores exógenos, decorrentes das próprias condições sociais de gênero nas quais as mulheres estão inseridas, incluem tanto a tradicional visão do amor materno quanto a da domesticidade. Quanto aos dificultadores endógenos, os estudos analisados pela autora destacam as relações sexistas ainda presentes em determinados sindicatos. As relações estabelecidas entre os 
homens e as mulheres, não raras vezes, carregam um viés discriminatório e segregador, atingindo negativamente a militância feminina.

Contudo, considerando que são as mulheres a maioria absoluta na categoria e que as mobilizações docentes continuam a acontecer massivamente no transcorrer de décadas, é de se perguntar se realmente podemos falar em pouca participação feminina, como afirmam algumas pesquisas. A questão não seria a não participação, mas a ampliação da participação de uma forma qualificada. No caso de nosso estudo, percebemos que alternativas para conquistar uma justiça distributiva ainda estão em processo de elaboração dentro das entidades ligadas à CNTE, como veremos.

\section{CARACTERIZAÇÃO DA CNTE}

No sistema brasileiro de ensino público, um número significativo de docentes, funcionárias/os da educação e pedagogas/os especialistas encontram-se representadas/os pela CNTE. Conhecida a partir do ano de 1990 por esta sigla, a entidade surgiu como Confederação dos Professores Primários do Brasil, criada em 1960, e posteriormente (em 1973) teve seu nome alterado para Confederação dos Professores do Brasil, quando do ingresso de professores secundários em sua base (FERREIRA, JR, 1998; VICENTINI; LUGLI, 2009).

Atualmente a Confederação reúne cerca de um milhão de sindicalizadas/os, através de 49 entidades a ela filiadas, o que corresponde a aproximadamente $57,5 \%$ do professorado do ensino básico público brasileiro (1.740.070 cargos, conforme o INEP [2016]). Com sua sede localizada em Brasília, a CNTE atua ao longo do território nacional, integrando trabalhadoras/es em educação principalmente das redes estaduais e/ou municipais do ensino básico, por meio de suas afiliadas situadas em 25 estados e no Distrito Federal (menos no estado do Rio de Janeiro). Em termos de estrutura, é formada por cinco instâncias: Congresso Nacional; Plenária Inter congressual, Conselho Nacional de Entidades; Conselho Fiscal; e Diretoria Executiva, dentro da qual se encontra a Secretaria de Relações de Gênero.

As ações e interesses da CNTE também abarcam questões de caráter internacional, especialmente por meio de sua filiação à Internacional da Educação, à Confederação dos Educadores Americanos e à Confederação Sindical Internacional. Em âmbito nacional, desde 1988 é filiada à CUT, central sindical com maior índice de representatividade de trabalhadores aferido pelo Ministério do Trabalho e Emprego em $2016(30,4 \%)$.

Dentre suas principais finalidades destacam-se a preocupação com os interesses e valorização da categoria, melhores condições econômicas e de trabalho, tendo recentemente mantido como uma das bandeiras o piso salarial nacional do magistério e para demais profissionais da área da educação (CNTE, 2014a). Posiciona-se em defesa de um ensino público, laico e gratuito. Com vistas a uma educação de maior qualidade social, tem conduzido suas lutas educacionais tencionando "incorporar a perspectiva de gênero, raça, etnia e orientação sexual no processo educacional formal e informal" (CNTE, 2014a, p. 82). Para tanto, conta com secretarias e coletivos específicos, como os Coletivos de Mulheres e o de LGBTs (fundado em 2010), dedicados às demandas educacionais e sociais sobre tais assuntos. 
A Secretaria de Relações de Gênero está incumbida da coordenação e desenvolvimento de atividades relacionadas a gênero e formulação de políticas e campanhas nacionais voltadas à participação das profissionais em educação (CNTE, 2014b). Suas ações são dirigidas a fortalecer o combate ao preconceito e discriminações de gênero no ambiente escolar, auxiliando na promoção da igualdade entre os sexos e na garantia de direitos de uma parcela da população mais vulnerável em esferas como as de gênero e orientação sexual, no âmbito da sociedade. Debates e políticas referentes a esses temas ganharam força, em especial com a publicação da Revista Mátria, lançada anualmente desde 2003, no dia 8 de março, em homenagem ao Dia Internacional da Mulher. A revista tem promovido ricas discussões sobre a vida profissional e pessoal de mulheres e discutido suas lutas e conquistas, sem abandonar o comprometimento acadêmico.

No âmbito institucional, a CNTE busca assegurar uma maior igualdade entre homens e mulheres em sua própria Diretoria Executiva e nas de seus sindicatos filiados, seguindo as orientações estabelecidas pela CUT e pela Internacional da Educação. Contudo, nem sempre essa perspectiva imperou. Segundo Marta Vanelli (2013), o percentual de representação feminina na direção da CNTE passou de $23 \%$ (gestão 1993/1995), para 33\% (gestão 1997/1999) e 67\% (gestões 2002/2005 e $2005 / 2008$, nas quais a presidência foi ocupada pela primeira e única mulher, Juçara Dutra Vieira). Na atual gestão (2017/2021) há paridade entre homens e mulheres. Ademais, não necessariamente as posições programáticas da Confederação têm conseguido estenderse linearmente às suas organizações afiliadas, como veremos a seguir.

\section{DIVISÃO DE PODER POR SEXO EM SINDICATOS DA CNTE}

Nas diretorias centrais dos sindicatos selecionados verificamos a proporcionalidade na ocupação de cargos por sexo. Agrupamos, a seguir, os resultados conforme as regiões do país.

$\mathrm{Na}$ região norte coletamos dados relativos às diretorias de seis sindicatos: SINTEAM/AM - Sindicato dos Trabalhadores em Educação do Estado do Amazonas; SINSEPEAP/AP - Sindicato dos Servidores Públicos em Educação do Amapá; SINTET-TO Sindicato dos Trabalhadores em Educação no Estado do Tocantins; SINTEPP/PA Sindicato dos Trabalhadores em Educação Pública do Pará; SINTER/RR - Sindicato dos Trabalhadores em Educação de Roraima; e SINTERO/RO - Sindicato dos Trabalhadores em Educação do Estado de Rondônia. O número de dirigentes varia de 15 a 37 em cada uma das entidades, totalizando 145 pessoas, das quais 59\% (85) são do sexo masculino e $41 \%$ (60) do sexo feminino. Todos os cargos de presidência ou que correspondem à presidência - como no caso do SINTER/RR - são ocupados por pessoas do sexo masculino; e os cargos de vice-presidência dividem-se entre os sexos (dois mais dois), destacando que dois dos sindicatos (SINTER/RR; SINTERO/RO) não possuem esse cargo. Os cargos que compõem as secretarias gerais e as tesourarias também em sua maioria são exercidos pelo sexo masculino (seis homens e quatro mulheres e sete homens e quatro mulheres, respectivamente). Quanto aos cargos das demais secretarias, $57 \%$ (65) são ocupados pelo sexo masculino e $43 \%$ (50) são ocupados pelo sexo feminino. 
Na região nordeste contabilizamos dados do SINTEAL/AL - Sindicato dos Trabalhadores em Educação de Alagoas; APLB/BA - APLB Sindicato dos Trabalhadores em Educação do Estado da Bahia; APEOC/CE - Associação dos Professores de Estabelecimentos Oficiais Ceará; SINTEP/PB - Sindicato dos Trabalhadores e Trabalhadoras em Educação do Estado da Paraíba; SINTEPE/PE - Sindicato dos Trabalhadores em Educação de Pernambuco; SINTE/PI - Sindicato dos Trabalhadores em Educação Básica Pública do Piauí; SINTE/RN - Sindicato dos Trabalhadores em Educação da Rede Pública do Rio Grande do Norte; e SINPROESEMMA/MA - Sindicato dos Trabalhadores em Educação Básica das Redes Públicas Estadual e Municipais do Estado do Maranhão. Verificamos que há uma variação na composição das diretorias entre 14 a 50 , somando 262 pessoas, sendo $47 \%$ (124) do sexo masculino e $53 \%$ (138) do sexo feminino. $69 \%$ (nove) dos cargos de presidência são ocupados pelo sexo masculino e $31 \%$ (quatro) pelo sexo feminino. Vale ressaltar que das quatro mulheres que ocupam a presidência, duas delas dividem o cargo com homens. Dos cargos de vice-presidência, observa-se que $62 \%$ (cinco) são do sexo masculino e $38 \%$ (três) do sexo feminino. Do mesmo modo que ocorre com o cargo de presidência, das três mulheres que ocupam o cargo de vice-presidência uma divide o cargo com um homem. Quanto à secretaria geral, temos $67 \%$ (12) dos cargos ocupados por mulheres e 33\% (seis) ocupados por homens, já os cargos de tesouraria são ocupados em $50 \%$ (nove) pelo sexo feminino e $50 \%$ (nove) pelo sexo oposto. As mulheres exercem 54\% (110) e os homens $46 \%$ (95) dos cargos das demais secretarias.

$\mathrm{Na}$ região centro-oeste do país, os dados relativos aos quatro sindicatos pesquisados: Federação dos Trabalhadores em Educação de Mato Grosso do Sul (FETEM/MS); Sindicato dos Professores no Distrito Federal (SINPRO/DF); Sindicato dos Trabalhadores em Educação de Goiás (SINTEGO/GO); e Sindicato dos Trabalhadores do Ensino Público de Mato Grosso (SINTEP/MT), demonstram variação na composição das diretorias de 20 a 39 pessoas, totalizando 127 diretores/as - 46\% (58) de homens e $54 \%$ (69) de mulheres. O sexo masculino ocupa $67 \%$ (quatro) dos cargos de presidência, enquanto o sexo feminino ocupa $33 \%$ (dois). Aliás, das duas mulheres ocupantes deste cargo, uma o divide com outros dois homens. Ressaltamos que, para fins de análise, inserimos os cargos de administração e patrimônio, constantes da diretoria colegiada do SINPRO/DF no quesito presidência, por serem os ocupantes destes cargos os que respondem juridicamente pelo sindicato. Quanto à vice-presidência, os três cargos existentes são ocupados por mulheres. Homens ocupam 40\% (dois) dos cargos de secretaria geral e mulheres $60 \%$ (três), enquanto que os cargos de tesouraria são ocupados em $56 \%$ (cinco) por homens e em $44 \%$ (4) por mulheres. As mulheres ocupam $54 \%$ (57) e os homens $46 \%$ (47) dos demais cargos das secretarias.

$\mathrm{Na}$ região sudeste, embora tenhamos selecionado apenas três sindicatos (SINDIUPES/ES - Sindicato dos Trabalhadores em Educação Pública do Espírito Santo; Sind-UTE/MG - Sindicato Único dos Trabalhadores em Educação de Minas Gerais; e APEOESP/SP - Sindicato dos Professores do Ensino Oficial do Estado de São Paulo), o número de membros das diretorias varia de 35 a 54 componentes, totalizando 125 pessoas, sendo $51 \%$ (64) homens e 49\% (61) mulheres. Para fins de análise - após consulta aos estatutos dos sindicatos -, atribuímos aos cargos de diretoria administrativofinanceira do SINDIUPES/ES e coordenação geral do Sind-UTE/MG a equivalência ao cargo de presidência, uma vez que respondem juridicamente pela entidade. À secretaria de 
organização do SINDIUPES/ES atribuímos a equivalência ao cargo de secretaria geral e, para o departamento administrativo-financeiro do Sind-UTE/MG, a equivalência de tesouraria. Desta forma, temos três ocupantes do cargo de presidência (e/ou sua equivalência) do sexo feminino e um do sexo masculino. A vice-presidência aparece apenas em uma das entidades (APEOESP/SP) e é ocupada pelo sexo masculino. Os cargos de secretaria geral (e/ou sua equivalência) são ocupados por $100 \%$ de pessoas do sexo masculino. Quanto aos cargos de tesouraria (e/ou sua equivalência), são ocupados por duas mulheres e um homem. Já as demais secretarias das estruturas de direção estão a cargo de $50 \%$ (57) de homens e $50 \%$ (56) de mulheres.

Sindicato dos Trabalhadores em Educação Pública do Paraná (APP/PR), Sindicato dos Trabalhadores em Educação da Rede Pública de Ensino do Estado de Santa Catarina (SINTE/SC) e Centro de Professores do Estado do Rio Grande do Sul - Sindicato dos Trabalhadores em Educação (CPERS/RS) são os três sindicatos pesquisados na região sul. Possuem uma composição menos díspar em termos da quantidade de integrantes em suas diretorias, entre 15 e 17 membros, num total de 49 pessoas, sendo que $47 \%$ (23) são do sexo masculino e $53 \%$ (26) são do sexo feminino. Quanto aos cargos, das três entidades duas (67\%) possuem em sua presidência homens e uma delas (33\%) uma mulher (CPERS/RS). A vice-presidência aparece no quadro de duas das entidades, sendo em uma (SINTE/SC) ocupada pelo sexo masculino e na outra (CPERS/RS) por duas pessoas, uma de cada sexo. Os cargos da secretaria geral são ocupados por $67 \%$ (2) de pessoas do sexo masculino e $33 \%$ (1) do feminino. Os números se invertem nos cargos de tesouraria - 33\% (1) de pessoas do sexo masculino e $67 \%$ (2) do feminino. Das demais secretarias, $57 \%$ (21) são ocupadas por mulheres e $43 \%$ (16) por homens.

Após vislumbrarmos as cifras relativas aos cargos das organizações selecionadas nas cinco regiões brasileiras, cabe-nos fazer últimos comentários. Das 708 pessoas que compõem as diretorias desses sindicatos, são exatos 50\% de homens e $50 \%$ de mulheres. $\mathrm{O}$ número de homens integrantes das diretorias excede o número de mulheres nas regiões norte e sudeste. Além disso, observando os cargos podemos verificar que $68 \%$ (21) das presidências das entidades estudadas são ocupadas pelo sexo masculino, enquanto que o sexo feminino ocupa $32 \%$ (10). Dentre as regiões, a sudeste é a única onde o número de mulheres exercendo a presidência é maior que o de homens, destacando-se também que, no Norte, não há mulheres docentes presidentes de seus sindicatos. Quanto à vice-presidência, embora por uma diferença pequena o sexo masculino ainda lidera - 53\% (10) dos cargos são ocupados por homens e $47 \%$ (9) ocupados por mulheres. Há um empate na presença de homens (20) e mulheres (20) em secretarias gerais, porém vale ressaltar que na região nordeste o número de mulheres ocupantes deste cargo (12/67\%) é o dobro do número de homens (6/33\%). Na tesouraria temos $52 \%$ (23) dos cargos exercidos por homens e $48 \%$ (21) por mulheres, sendo que nas regiões sudeste e sul o número de mulheres ocupantes deste cargo é superior ao número de homens. As demais secretarias que integram as diretorias apresentam $51 \%$ (294) de mulheres e $49 \%$ (280) de homens. Apenas nas regiões norte e sudeste o número de homens ocupantes dessas secretarias é maior do que de mulheres, conforme podemos verificar no quadro abaixo. 
FERREIRA, M. O. V.; ORSATO, A.; CORONEL, M. C. V. K.; SANTOS, L. P.

Cargos de direção, segundo o sexo, em sindicatos selecionados filiados à CNTE, conforme regiões do Brasil - 2015

\begin{tabular}{|c|c|c|c|c|c|c|c|c|c|c|c|c|c|}
\hline \multirow[t]{2}{*}{ Regiões } & \multicolumn{2}{|c|}{ Presidência } & \multicolumn{2}{|c|}{$\begin{array}{c}\text { Vice- } \\
\text { Presidência }\end{array}$} & \multicolumn{2}{|c|}{$\begin{array}{c}\text { Secretaria } \\
\text { Geral }\end{array}$} & \multicolumn{2}{|c|}{ Tesouraria } & \multicolumn{2}{|c|}{ Secretarias } & \multicolumn{2}{|c|}{ Total } & \multirow[t]{2}{*}{$\begin{array}{l}\text { Total } \\
\text { Geral }\end{array}$} \\
\hline & $\mathrm{H}$ & $M$ & $\mathrm{H}$ & $M$ & $\mathrm{H}$ & $M$ & $\mathrm{H}$ & $M$ & $\mathrm{H}$ & $M$ & $\mathrm{H}$ & $M$ & \\
\hline NORTE & 5 & 0 & 2 & 2 & 6 & 4 & 7 & 4 & 65 & 50 & 85 & 60 & 145 \\
\hline NORDESTE & 9 & 4 & 5 & 3 & 6 & 12 & 9 & 9 & 95 & 110 & 124 & 138 & 262 \\
\hline CENTRO-OESTE & 4 & 2 & 0 & 3 & 2 & 3 & 5 & 4 & 47 & 57 & 58 & 69 & 127 \\
\hline SUDESTE & 1 & 3 & 1 & 0 & 4 & 0 & 1 & 2 & 57 & 56 & 64 & 61 & 125 \\
\hline SUL & 2 & 1 & 2 & 1 & 2 & 1 & 1 & 2 & 16 & 21 & 23 & 26 & 49 \\
\hline Totais - Brasil & 21 & 10 & 10 & 9 & 20 & 20 & 23 & 21 & 280 & 294 & 354 & 354 & 708 \\
\hline
\end{tabular}

Fonte: elaboração própria com dados coletados nos sítios das organizações.

Destacamos ainda que, no Norte, o SINSEPEAP/AP apresenta igualdade de sexo em termos de número total de ocupantes de cargos. No Nordeste maior proximidade à igualdade é encontrada no SINPROESEMMA/MA. No Centro-Oeste, é o SINPRO/DF a apresentar maior igualdade entre os sexos, e no Sudeste, a APEOESP/SP. Finalmente, destaca-se, no Sul, a circunstância de que os três sindicatos selecionados apresentam proporções semelhantes.

Embora o número de mulheres exercendo docência na educação básica brasileira supere, como vimos, os $80 \%$ do professorado, nas entidades de representação dessa classe o número de homens exercendo cargos de poder é idêntico ao número de mulheres. Mas o que separa definitivamente homens de mulheres é o exercício da presidência, pois neste caso a representação masculina corresponde a mais de $2 / 3$. Assim, os dados nos permitem evidenciar empiricamente a alegada superioridade numérica masculina nas direções sindicais de trabalhadores em educação. Essa indicação foi comprovada no que se refere ao principal cargo de comando e visibilidade dos sindicatos, e especialmente em determinadas partes do país. Esse resultado se aproxima daqueles relatados em estudos, de caráter variado, que têm se ocupado do tema: Alves (1999), que visou às mulheres na condição de presidente das seções sindicais do ANDES-SN (Sindicato Nacional dos Docentes das Instituições de Ensino Superior), em número inferior à sua presença nas bases do mesmo; Sartori (2001), que verificou a presença maior de mulheres em áreas de formação sindical e de cultura e de homens em cargos de maior prestígio, no que se refere ao movimento sindical ligado à CUT em Florianópolis; Ferreira (2004), que encontrou resultados semelhantes no CPERS/SINDICATO, entre 1978/1999; Trópia (2015), que evidenciou, entre homens e mulheres militantes do ANDES-SN, condições desiguais para o exercício do mandato sindical (os homens têm maior liberação total ou parcial para tal exercício).

\section{CONSIDERAÇÕES FINAIS}

Nosso propósito, ao realizar esse levantamento numa amostra significativa de entidades filiadas à CNTE, foi vislumbrar como as mesmas constituem suas direções em termos da proporcionalidade entre homens e mulheres e que lugares estas ocupam na distribuição de poder sindical. Percebemos certa equiparação entre os sexos nas diretorias, a despeito de que a imensa maioria da base da categoria seja composta por mulheres, corroborando a existência de uma sub-representação feminina dentro das 
organizações sindicais. Desde o ponto de vista unicamente das nominatas das diretorias, evidenciou-se também uma sub-representação feminina no que se refere ao posto de maior poder e prestígio, o cargo de presidente, dado que reafirma o apresentado em nosso referencial: ainda que as mulheres não sejam excluídas do mundo público, sua inserção tem ocorrido por atribuição de um status inferior, demonstrando que a subordinação feminina está enraizada nas esferas privada e pública (RANGEL, 2008). Ou, parafraseando Pateman (1993), a diferença sexual é uma diferença política, verificada no exercício do poder político, seja nas instâncias representativas dos Estados democráticos, seja em organizações como os sindicatos, entre eles os da educação, mesmo quando as propostas programáticas para minorias sejam mais inclusivas, como se percebe nas orientações apresentadas pela CNTE.

A permanência de uma condição de desigualdade quanto à representatividade feminina na esfera pública, especialmente nas instâncias onde se tomam decisões, é uma situação que somente se reproduz devido à assimetria de poder entre homens e mulheres em diferentes esferas. Essa desigualdade de poder constitui-se como uma construção histórica que sempre relegou as mulheres a uma situação de subordinação perante o homem, ao mesmo tempo em que lhes atribuía o lar, a família, como espaços de atuação preferencial, não por acaso considerados como não políticos pela teoria política liberal.

Contudo, mecanismos cotidianos que diferenciam a atuação de mulheres e homens ou que dificultam uma participação mais equitativa das primeiras nas disputas sindicais podem ser mais bem apreendidos por técnicas com caráter qualitativo, atividade seguinte de pesquisa em curso, voltada a descobrir o que motiva professoras a engajarse em atividades sindicais e qual a perspectiva adotada pela CNTE quanto ao tratamento às questões de gênero e diversidade sexual. Como já comentamos, nossa tese argumenta que a separação esfera pública/privada, demarcadora de identidades e de representações de gênero, também opera sobre as disputas e o cotidiano das organizações sindicais, limitando a participação paritária das mulheres. Neste sentido, a discussão futura deve ser conduzida no sentido de desvelar as formas de expressão do habitus de gênero e as estratégias a serem utilizadas para diminuir seus danos. EDUCATION WORKERS 
FERREIRA, M. O. V.; ORSATO, A.; CORONEL, M. C. V. K.; SANTOS, L. P.

ABSTRACT: The article is based on the lack of studies about gender at Education Unions in Brazil. We observed that the few existing works focus on discussing the union participations of the women without focusing more directly in the position of the unions themselves. Knowing that the differences of gender and sexual diversity are components of the processes of distribution of power and social inequality, we aimed to check the proportionality between men and women in executive positions at unions affiliated to CNTE. To this end, we conduct surveys on the websites of CNTE and its unions. Concerning the division of power by gender, we noticed that, similarly to what happens in other institutional spaces such as the Brazilian Legislative and Executive Powers, the male presence is even bigger.

KEYWORDS: Gender relations. Woman's participation. Teacher's unionism. CNTE.

\section{GÉNERO Y REPRESENTACIÓN POLÍTICA: UN ESTUDIO SOBRE LA REPRESENTACIÓN SINDICAL DE TRABAJADORAS / ES EN EDUCACIÓN}

RESUMEN: Inicialmente el artículo trata de la insuficiencia de estudios sobre género en sindicatos de educación en Brasil. Observamos que los escasos trabajos existentes se dedican a discutir la participación sindical femenina sin abordar de forma más directa la posición de los sindicatos. Teniendo en cuenta que diferencias de género y diversidad sexual son componentes de procesos de distribución de poder y desigualdad social, nuestro objetivo fue verificar la proporcionalidad entre hombres y mujeres ocupantes de cargos directivos en sindicatos filiados a CNTE. Para tanto, recolectamos datos en los sitios de la CNTE y sus sindicatos. Respecto a la división de poder por sexo, constatamos que, tal cual en otros espacios institucionales, como en los poderes Legislativo y Executivo brasileños, la presencia masculina todavía es más grande.

PALABRAS CLAVE: Relaciones de género. Participación de la mujer. Sindicatos de trabajadores de la educación. CNTE.

NOTA

1) Trabalho realizado com apoio do CNPq, sob forma de Auxílio à Pesquisa e Bolsa de Produtividade à Pesquisa. Uma versão preliminar deste texto foi apresentada no V Seminario Internacional de la Red de Investigadores sobre Asociacionismo y Sindicalismo de los Trabajadores de la Educación Rede ASTE, Rosario (Argentina), 2015.

\section{REFERÊNCIAS}

ALMEIDA, J. S. de. Mulher e educação: a paixão pelo possível. São Paulo: UNESP, 1998.

ALVES, J. E. D. A participação da mulher na ANDES-SN. Universidade e Sociedade, Brasília, n. 18, p. 96-102, mar. 1999.

BOURDIEU, P. A dominação masculina. Rio de Janeiro: Bertrand Brasil, 1999.

CASTRO, M. G. Gênero e poder no espaço sindical. Estudos Feministas, Rio de Janeiro, v. 3, n. 1, p. 29-51, 1995. 
CNTE. Caderno de Resoluções do $32^{\circ}$ Congresso Nacional da Confederação Nacional dos

Trabalhadores em Educação: educação, desenvolvimento e inclusão social. Brasília: CNTE, 2014a. Disponível em: http://www.cnte.org.br/images/stories/2014/caderno_de_resolucoes_2014.pdf. Acesso em: 23 mar. 2017.

CNTE. Estatuto. Brasília: CNTE, 2014b.

CNTE. Gênero e diversidade sexual na escola; a CNTE apoia os movimentos sociais. Retratos da Escola, Brasília, v. 9, n. 16, p. 187-194, jan./jun. 2015.

CORONEL, M. C. V. K. Gênero e sindicalismo docente: uma análise da produção acadêmica na pósgraduação. 2014. Dissertação (Mestrado em Educação) - Faculdade de Educação, Universidade Federal de Pelotas, Pelotas, 2014.

CUT - Central Única dos Trabalhadores. 30 anos de Política de Gênero: a história de luta das mulheres no movimento sindical. Disponível em: http://www.cut.org.br/imprimir/standpoint/c55e0217f0c460f3bc793d921e226176/. Acesso em: 23 mar. 2017.

FERREIRA JR., A. Sindicalismo e proletarização: a saga dos professores brasileiros. 1998. 303f. Tese (Doutorado em História Social), Universidade de São Paulo, São Paulo, 1998.

FERREIRA, M. O. V. Mulheres e homens em sindicato docente: um estudo de caso. Cadernos de Pesquisa, São Paulo, v. 34, n. 122, p. 391-410, 2004.

. Por que o gênero é importante para entender-se o sindicalismo docente? In: BAUER, C., et alii, (orgs.). Sindicalismo e associativismo dos trabalhadores em educação no Brasil. v. 2. Jundiaí: Paco Editorial, 2015. p. 303-317.

FRASER, N. Reenquadrando a justiça em um mundo globalizado. Lua Nova, São Paulo, n. 77, p. 1139, 2009.

GILLIGAN, C. Uma voz diferente; psicologia da diferença entre homens e mulheres da infância à idade adulta. Rio de Janeiro: Rosa dos Tempos, s.d.

GIULANI, P. C. Os movimentos de trabalhadoras e a sociedade brasileira. In: DEL PRIORE, M. (org.). História das mulheres no Brasil. 5. ed. São Paulo: Contexto, 2001. p. 640-667.

HIRATA, H.; KERGOAT, D. Divisão sexual do trabalho profissional e doméstico: Brasil, França, Japão. In: COSTA, A. de O. et al. (orgs.). Mercado de trabalho e gênero; comparações internacionais. Rio de Janeiro: FGV, 2008. p. 263-278.

HUMPHREY, J. Sindicato; um mundo masculino. Novos Estudos Cebrap, São Paulo, v. 2, n. 1, p. 4752, abr. 1983.

INEP - Instituto Nacional de Estudos e Pesquisas Educacionais Anísio Teixeira. Sinopse Estatística da Educação Básica 2015. Brasília: INEP, 2016. Disponível em: 
FERREIRA, M. O. V.; ORSATO, A.; CORONEL, M. C. V. K.; SANTOS, L. P.

http://portal.inep.gov.br/web/guest/sinopses-estatisticas-da-educacao-basica. Acesso em: 23 mar. 2017.

KERGOAT, D. Divisão sexual do trabalho e relações sociais de sexo. In: HIRATA, H. et al. (orgs.). Dicionário crítico do feminismo. São Paulo: UNESP, 2009. p. 67-75.

KYMLICKA, W. Feminismo. In: Paulo: Martins Fontes, 2006. p. 303-373.

LOURO, G. L. Mulheres na sala de aula. In: DEL PRIORE, M. (org.). História das mulheres no Brasil. 5. ed. São Paulo: Contexto, 2001. p. 443-481.

MARQUES, L. A.; COSTA, P. A participação das mulheres nas centrais sindicais. Revista do Observatório Brasil da Igualdade de Gênero, Brasília, Dossiê mulheres e poder, p. 86-88, dez. 2009.

MIGUEL, L. F. Política de interesses, política do desvelo: representação e "singularidade feminina". Estudos Feministas, Florianópolis, v. 9, n. 1, p. 253-267, 2001.

MIGUEL, L. F.; BIROLI, F.. Introdução: teoria política feminista, hoje. In: política feminista; textos centrais. Vinhedo: Horizonte/UFF, 2013. p. 7-54. (orgs.). Teoria

PATEMAN, C. O contrato sexual. São Paulo: Paz e Terra, 1993.

RANGEL, P. A Câmara das Deputadas. Um panorama da representação parlamentar feminina em Argentina, Brasil e Uruguai. 2008. Dissertação (Mestrado em Ciência Política) - IUPERJ, Rio de Janeiro, 2008.

ROGERAT, C.; ZYLBERBERG-HOCQUARD, M.-H.. Sindicatos. In: HIRATA, H. et al. (orgs.). Dicionário crítico do feminismo. São Paulo: UNESP, 2009. p. 236-241.

SANTOS, M. A. A participação das mulheres na estrutura sindical. 2011. Disponível em: http://www.fsindical.org.br/artigos/a-participacao-das-mulheres-na-estrutura-sindical. Acesso em: 23 de mar. 2017.

SARTORI, A. J. Homens e relações de gênero entre sindicalistas de esquerda em Florianópolis. In: BRUSCHINI, C.; PINTO, C. R. (orgs.). Tempos e lugares de gênero. São Paulo: Fundação Carlos Chagas/Editora 34, 2001. p. 216-239.

SOUZA-LOBO, E. A classe operária tem dois sexos. trabalho, dominação e resistência. São Paulo: Brasiliense/SMC, 1991.

STREET, S. El género como categoría para repensar al sujeto popular: dos generaciones en el activismo femenino del magisterio democrático mexicano. In: GALVÁN LAFARGA, L. E.; LÓPEZ PÉREZ, O. (coords.). Entre imaginarios y utopías. historias de maestras. México: Publicaciones de la Casa Chata, 2008. p. 395-420.

TRÓPIA, P. V. Condições de trabalho dos docentes militantes. In: ENCONTRO NACIONAL DA ASSOCIAÇÃO BRASILEIRA DE ESTUDOS DO TRABALHO, 14., 2015, UNICAMP, Campinas. p. 1-11 (mimeo). 
VANELLI, M. A mulher brasileira e sua participação nos cargos de decisão sindicais. Revista Mátria, Brasília, n. 11, mar. 2013, p. 50-51.

VICENTINI, P. P.; LUGLI, R. G. História da profissão docente no Brasil. representações em disputa. São Paulo: Cortez, 2009.

WILLIAMS, C. L. The Glass Escalator: Hidden Advantages for Men in the "Female" Professions. Social Problems, v. 39, n. 3, p. 253-267, aug./1992.

MÁrcia Ondina Vieira Ferreira: Doutora em Sociologia (Universidade de Salamanca/Espanha) e Bolsista de Produtividade em Pesquisa ( $\mathrm{CNPq}$ ), atua no PPGEducação/UFPel pesquisando e orientando trabalhos sobre as temáticas: trabalho docente, relações de gênero e sindicalismo docente.

E-mail:marciaondina@uol.com.br

AndREIA OrSATO: Doutora em Ciência Política (UFRGS), realiza estágio pós-doutoral no PPGEducação/UFPel e desenvolve estudos sobre participação política, gênero e democracia.

E-mail: andreiaorsato@gmail.com

MÁrcia Cristiane Vlölz Klumb Coronel: Mestre e Doutoranda em Educação no PPGEducação/UFPel e professora da EMEF Presidente Floriano Peixoto (Novo Hamburgo), desenvolve estudos sobre sindicalismo docente e gênero.

E-mail: marciavolz@yahoo.com.br

LuCiano Pereira dos Santos: Mestre e Doutorando em Educação no PPGEducação/UFPel, desenvolve estudos sobre sindicalismo docente, sênero sexualidades. E-mail: lucianopereiraluciano@smail.com 